\title{
Correction to: Understanding Cancer Survivors' Educational Needs about Prescription Opioid Medications: Implications for Cancer Education and Health Literacy
}

\author{
Dinorah Martinez Tyson ${ }^{1} \cdot$ Melody N. Chavez $^{1} \cdot$ Barbara Lubrano $^{2} \cdot$ Paige Lake $^{1} \cdot$ Ana Gutierrez $^{1}$. \\ Victoria K. Marshall ${ }^{3} \cdot$ Khary K. Rigg $^{4} \cdot$ Heather Henderson ${ }^{5} \cdot$ Smitha Pabbathi $^{6} \cdot$ Peggie Sherry $^{6} \cdot$ Sahana Rajasekhara $^{2}$
}

Published online: 18 June 2021

(C) American Association for Cancer Education 2021

\section{Correction to: Journal of Cancer Education (2021) 36:215-224}

https://doi.org/10.1007/s13187-021-01957-9

The original version of this article unfortunately contained a mistake. The last sentence under the header Data Collection should read:

Informed consent was obtained from each participant, and ethical approval was obtained by the Moffitt Scientific
Review Committee and the University of South Florida Institutional Review Board.

The original article has been corrected.

Publisher's Note Springer Nature remains neutral with regard to jurisdictional claims in published maps and institutional affiliations.
The online version of the original article can be found at https://doi.org/ 10.1007/s13187-021-01957-9

Dinorah Martinez Tyson

dmtyson@usf.edu

1 College of Public Health, University of South Florida, 13201 Bruce B. Downs Blvd, MDC 56, Tampa, FL 33612-3805, USA

2 Moffitt Cancer Center, 12902 Magnolia Drive, Tampa, FL 33612, USA

3 College of Nursing, University of South Florida, 12912 Bruce B. Downs, MDC 22, Tampa, FL 33612, USA

4 Department of Mental Health Law and Policy, University of South Florida, 13301 Bruce B. Downs Blvd, Tampa, FL 33612, USA

5 Department of Anthropology, University of South Florida, 4202 E. Fowler Ave. SOC 107, Tampa, FL 33620, USA

6 Faces of Courage, 10006 Cross Creek Blvd \#519, Tampa, FL 33647-2595, USA 